\title{
Cytogenetic Evaluation of Some Genera of Persian Phaseolus
}

\author{
M. B. Sadeghi*, F. Khialparast, M. Sabokdast, M. Omidi and M. R. Naghavi \\ *Department of Agronomy and Plant Breeding, Faculty of Agricultural Science and \\ Engineering, University of Tehran, Karaj, Iran
}

Received November 26, 2011; accepted March 31, 2012

\begin{abstract}
Summary This research was carried out to evaluate the cytogenetic diversity of Persian beans with using an image analysis system. Ploidy levels of genotypes were determined from $x=9$ ( 2 diploids), $x=10$ ( 2 diploids) and $x=11$ ( 9 diploids). The highest chromatin length belonged to genotype 5 $(12.501 \mu \mathrm{m})$ and the lowest to genotype $13(5.042 \mu \mathrm{m})$. With regards to the Stebbins two-way table, $\mathrm{I}, \mathrm{L}$, and $\mathrm{F}$ genotypes divided to group a $2 \mathrm{~A} ; \mathrm{A}, \mathrm{B}$, and $\mathrm{N}$ genotypes divided to group $1 \mathrm{~B}$; and the rest of the genotypes divided to group $2 \mathrm{~B}$. The most asymmetric karyotype between and within chromosomes was genotype N. Five important karyotype indexes that are related to the cytogenetic diversity of Persian beans were studied in Completely Randomized Design (CRD) with 3 replications, at the University of Tehran in 2010. The results of ANOVA showed significant differences among genotypes in all karyotype indexes (A, \%Syi, \%TF, SC, $A_{2}$ and $\left.A_{1}\right)$. Principal components analysis classified the 5 karyotype indexes in to 2 new components that explained $96.41 \%$ of total variations. The first component explained $65.34 \%$ of total variations that mainly included diastatic arm ratio, $\mathrm{CI}, A_{1}$, TF, Syi and $\mathrm{A}$. The second component explained $31.28 \%$ of total variations that mainly included TL, SA, LA and $A_{2}$. Cluster analysis by the Ward method classified characters in to 3 groups. The results showed that genotypes were significantly different in all characters; therefore analysis of these clusters showed the most genetic distance to be between $\mathrm{N}$ and $\mathrm{H}$.
\end{abstract}

Key words Chromosomes, Karyotype indexes, Bean, Completely Randomized Design.

Cereals play an important role to support both qualitative and quantitative food needs of human societies, especially in developing countries in Asia, Africa and Latin America. Also these plants are important in soil fertilization processes and stabilize significant amounts of atmospheric nitrogen annually. The common bean (Phaseolus vulgare) is a diploid plant $(2 n=22)$ from the Fabaceae family has a genome size of about $600 \mathrm{Mb}$ and its origins can be traced to south America (Arumuganathan et al. 1991). The Papilionideae subfamily belongs to the Fabaceae family. This subfamily has important economic genera like Glysin (Soybean), Phaseolus (American beans) and Vigna (Asiatic beans). The common bean is one of the smaller genome-sized species and most karyotype studies so far have related to chromosome number; however, today many genetic maps for the common bean are being presented (Gepts et al. 2008). Several BAC (bacterial artificial chromosome) libraries exist or are being developed for various genotypes of Phaseolus (Pedrosa et al. 2009, Kami et al. 2006, Vanhouten and MacKenzie 1999) Karyotype definition is the arrangement of basic chromosomes from long to short size. Some of the symmetric karyotype indexes are:

1) TF\% (Total form percentage): closer to $50 \%$ means higher number of metacentric chromosomes than telocentric and acrocentric chromosomes.

$\mathrm{TF} \%=\frac{\text { Total sum of short arms lengths }}{\text { Total sum of chromosome lengths }} \times 100$

* Corresponding author, e-mail: mbsadeghi@ut.ac.ir

DOI: $10.1508 /$ cytologia. 77.225 
This index has been used by Mercado-Ruaro and Delgado-Salinas (1998) on some bean genotypes.

2) $A_{1}$ (Inter chromosomal asymmetry index):

$$
A_{1}=1-\frac{\sum_{i=1}^{n} \frac{q_{i}}{p_{i}}}{n}
$$

$q=$ short arm length

$p=$ long are length

$n=$ number of studied cells

And $A_{2}$ (intra chromosomal asymmetry):

$S_{\mathrm{CL}}=$ chromosomes length standard deviation

$$
A_{2}=\frac{S_{\mathrm{CL}}}{\bar{X}_{\mathrm{CL}}}
$$

$X_{\mathrm{CL}}=$ mean chromosome length

Seijo and Fernandez 2003, used $A_{2}$ to analysis some Lathyrus species.

3) Syi (Karyotype symmetry index) determined by Greilhuber and Speta (1976).

$$
\text { Syi }=\frac{\text { Mean length of short arms }}{\text { Mean length of long arms }} \times 100
$$

4) A (Karyotype asymmetry index) presented by Watanabe et al. 1999, Paszko 2006

$$
\begin{aligned}
A & =\frac{\sum \frac{p_{i}-q_{i}}{p_{i}+q_{i}}}{n} \\
q & =\text { short arm length } \\
p & =\text { long arm length } \\
n & =\text { number of studied cells }
\end{aligned}
$$

Cytogenetic and karyotype studies are one of the methods for diversity evaluation in plants. It is obvious that species with more similarity in chromosomal properties are closer to each other and this can help to select and produce better lines and varieties in breeding programs. The goal of this research is to determine karyotype diversity in some Iranian beans.

\section{Materials and methods}

In order to evaluate karyotype diversity in some genera of Phaseolus, 13 genotypes provided by the gene bank of Tehran University were studied. After seed disinfection with 5\% hypo sodium chloride for $7 \mathrm{~min}$, they were planted in petri dishes under $80 \%$ humidity, $23^{\circ} \mathrm{C}$ and $12 \mathrm{~h}$ light period. When seeds germinated and $0.8-1.5 \mathrm{~cm}$ radicle the appeared, the apical section was separated. Then pre treatment $(0.5 \%$ cholchicine solution), fixation (acetic acid-ethanol $3: 1,18 \mathrm{~h}$ ), washing (sodium acetate $2.5 \mathrm{M}$ ), hydrolysis (chloridric acid $1 \mathrm{~N}, 10 \mathrm{~min}, 55^{\circ} \mathrm{C}$ ), washing with distilled water and staining with acetoorcein $1 \%$ for $24 \mathrm{~h}$ in room temperature were performed. $1-2 \mathrm{~mm}$ apical radicle were transferred onto the lam and then squashed with 1 drop of glycerol-acetic acid $45 \%$. A chromosomal study was performed with imaging analysis system with $\times 1800$ enlargement. 


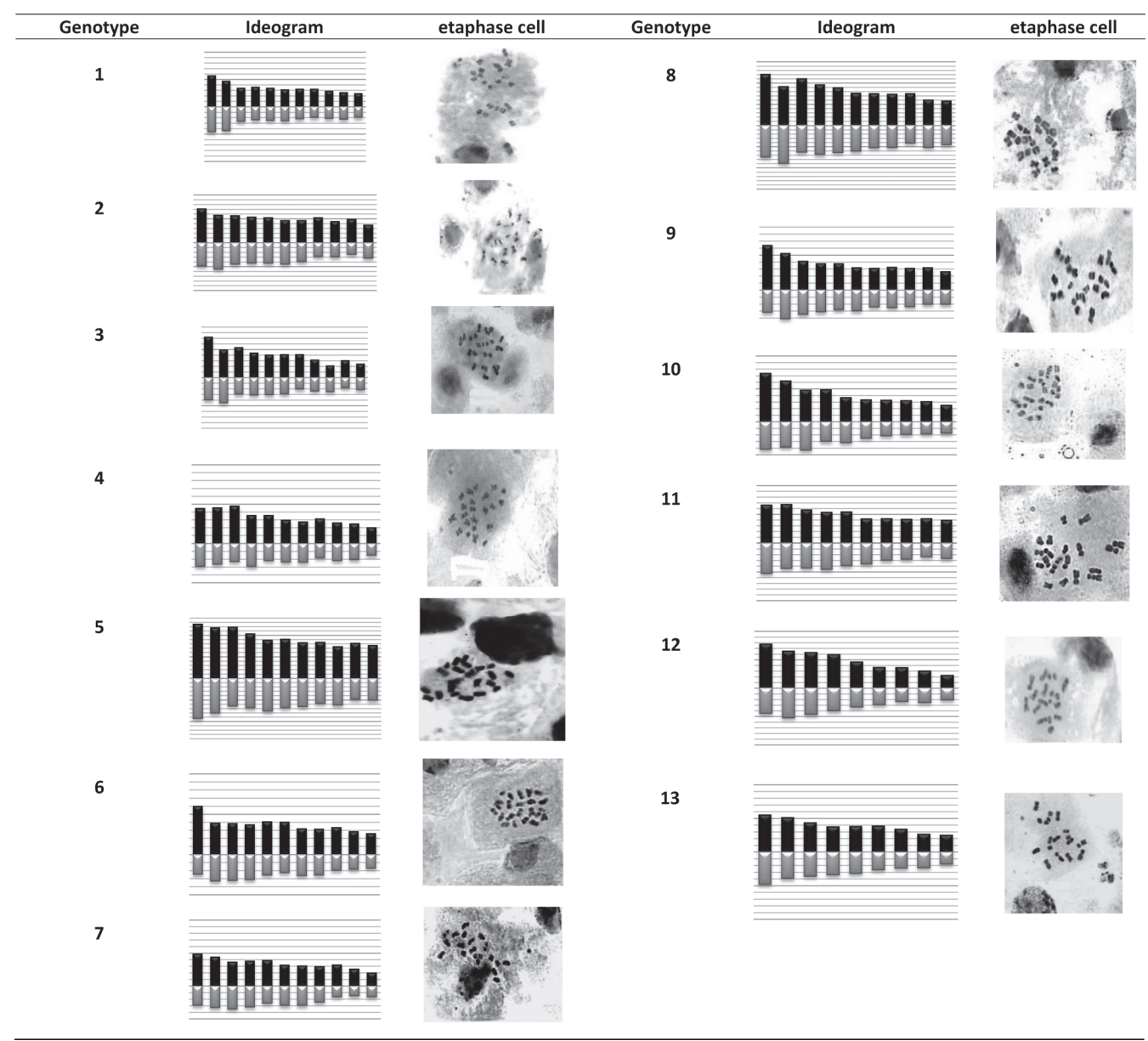

Fig. 1. Photos of metaphase root cells of beans with their ideograms

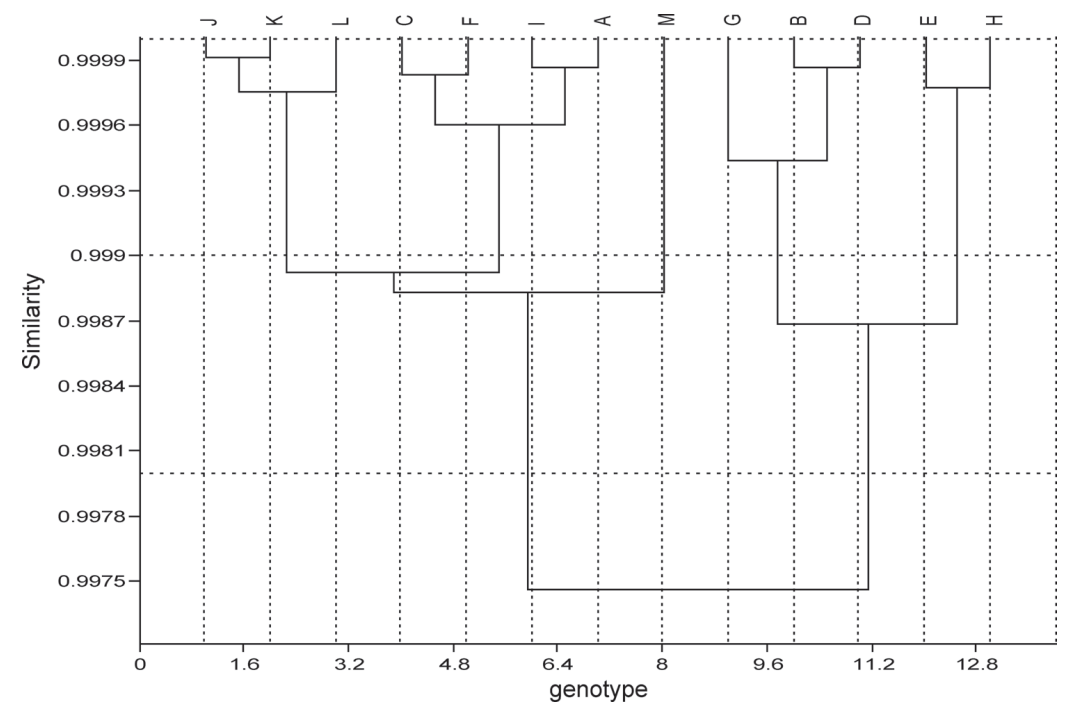

Fig. 2. Dendrogram for karyotype traits of Iranian beans. 
Table 1. Karyotpe characteristics of studied beans

\begin{tabular}{cccccccccc}
\hline \hline Genotype & $\begin{array}{c}\text { Karyotype } \\
\text { formula }\end{array}$ & A & \%Syi & \%TF & SC & $A_{2}$ & $A_{1}$ & $X$ & $2 n$ \\
\hline 1 & $5 \mathrm{~m}+6 \mathrm{sm}$ & 0.120 & 78.57 & 44 & $1 \mathrm{~B}$ & 0.065 & 0.214 & 11 & 22 \\
2 & $9 \mathrm{~m}+2 \mathrm{sm}$ & 0.223 & 63.27 & 38.75 & $1 \mathrm{~B}$ & 0.099 & 0.365 & 11 & 22 \\
3 & $4 \mathrm{~m}+7 \mathrm{sm}$ & 0.151 & 73.66 & 42.41 & $2 \mathrm{~B}$ & 0.055 & 0.263 & 11 & 22 \\
4 & $5 \mathrm{~m}+6 \mathrm{sm}$ & 0.22 & 64.16 & 39.08 & $2 \mathrm{~B}$ & 0.091 & 0.36 & 11 & 22 \\
5 & $5 \mathrm{~m}+6 \mathrm{sm}$ & 0.193 & 67.47 & 40.28 & $2 \mathrm{~A}$ & 0.05 & 0.323 & 11 & 22 \\
6 & $7 \mathrm{~m}+4 \mathrm{sm}$ & 0.183 & 68.81 & 40.76 & $2 \mathrm{~B}$ & 0.044 & 0.31 & 11 & 22 \\
7 & $8 \mathrm{~m}+3 \mathrm{sm}$ & 0.266 & 58.22 & 36.79 & $2 \mathrm{~B}$ & 0.119 & 0.42 & 11 & 22 \\
8 & $5 \mathrm{~m}+6 \mathrm{sm}$ & 0.231 & 62.02 & 38.27 & $2 \mathrm{~A}$ & 0.082 & 0.375 & 11 & 22 \\
9 & $10 \mathrm{~m}+1 \mathrm{sm}$ & 0.149 & 74.40 & 42.65 & $2 \mathrm{~B}$ & 0.093 & 0.258 & 11 & 22 \\
10 & $7 \mathrm{~m}+3 \mathrm{sm}$ & 0.211 & 64.41 & 39.18 & $2 \mathrm{~B}$ & 0.099 & 0.346 & 10 & 20 \\
11 & $8 \mathrm{~m}+2 \mathrm{sm}+1 \mathrm{t}$ & 0.220 & 63.09 & 38.68 & $2 \mathrm{~A}$ & 0.168 & 0.36 & 10 & 20 \\
12 & $7 \mathrm{~m}+3 \mathrm{sm}$ & 0.192 & 68.46 & 40.64 & $2 \mathrm{~B}$ & 0.147 & 0.32 & 9 & 18 \\
13 & $8 \mathrm{~m}+2 \mathrm{sm}$ & 0.117 & 79.02 & 44.13 & $1 \mathrm{~B}$ & 0.023 & 0.209 & 9 & 18 \\
\hline
\end{tabular}

Table 2. Variance analysis of karyotype traits

\begin{tabular}{lcccccc}
\hline \hline & & \multicolumn{5}{c}{ Means of squares } \\
\cline { 3 - 7 } S.O.V & DF & CL & TL & AR & SA & LA \\
\hline Genotype & 13 & $14.55^{* *}$ & $16.37^{* *}$ & $0.05^{* *}$ & $2.45^{* *}$ & $6.35^{* *}$ \\
Error & 28 & 4.04 & 0.87 & 0.01 & 0.18 & 0.32 \\
CV (\%) & - & 4.98 & 11.22 & 8.67 & 12.68 & 11.51 \\
\hline
\end{tabular}

ns: No significance $*$ Significant $(5 \%) \quad * *$ Highly significant $(1 \%)$.

Karyotypes were prepared by a micro measure software and 3 metaphase cells (replication) were selected from each slide and the following indexes calculated: TL (total chromosome length), S (total sum of short arms length), L (total sum of long arms length), L/S (arm ratio), L-S ( $d$-value), $\mathrm{CI} \%=(\mathrm{S} / \mathrm{L}+s)$ (centromeric index), RL\%=(Realtive Length), $\mathrm{S} \%=($ shortest chromosome length/longest chromosome length) $\times 100$ (relative length of shortest chromosome), DRL (different relative length of large to short chromosome), $A_{1}$ (Inter chromosomal asymmetry index), $A_{2}$ (intra chromosomal asymmetry), TF\% (Total form percentage), Syi (Karyotype symmetry index), A (Karyotype asymmetry index). The Levan method was used to determine chromosome kind and karyotype formula. PCA analysis with SPSS software was performed to determine the role of each trait in genetic diversity and cluster analysis with Past software performed to grouping genotypes.

\section{Results and discussion}

Table 1 shows the characteristics of chromosome numbers, karyotype formula, $A_{1}$ and $A_{2}$ indexes, Stebbins classes, TF\%, Syi and A for each genotype. All genotypes were diploids but the basic chromosome was different $(X=9,10,11)$ which represents genetic diversity in the material. The Stebbins index for genotypes 6, 9, 12 was 2A, for genotypes 1,2,13 was 1B and for the rest of the genotypes was 2B. The highest amount of Syi\% (78.57) was related to genotype 1, which means this genotype has the most symmetric karyotype. In comparison with the trend of $A_{1}$ and $A_{2}$ indices, genotype 8 had the most inter-chromosomal asymmetry and genotype 12 had the most intra-chromosomal asymmetry. Genotypes 1 and 13 had the lowest amount of $A_{1}$ and $A_{2}$.

Variance analysis for 13 genotypes based on CRD with 3 replications showed high significant differences between genotypes for all traits which represents a high level of genetic diversity in 
Table 3. Mean comparison between genotypes for karyotype traits

\begin{tabular}{lllllllllll}
\hline \hline Genotype & LA & & SA & & Arm & & TL & & \multicolumn{2}{c}{ CI } \\
\hline AA & 4.58 & def & 3.6 & cde & 1.27 & d & 8.19 & d & 43.95 & a \\
BB & 5.44 & cd & 3.44 & efd & 1.58 & abc & 8.89 & cd & 38.8 & bcd \\
CC & 4.97 & de & 3.67 & bcde & 1.35 & bcd & 8.66 & cd & 42.41 & ab \\
DD & 6.09 & bc & 3.91 & bcd & 1.56 & abc & 10.01 & bc & 38.98 & bcd \\
EE & 7.46 & a & 5.03 & a & 1.48 & abc & 12.5 & a & 40.32 & abcd \\
FF & 5.26 & cd & 3.62 & cde & 1.45 & bcd & 8.89 & dc & 40.8 & abc \\
GG & 4.65 & def & 2.7 & hfg & 1.73 & a & 7.36 & de & 36.65 & d \\
HH & 7.14 & a & 4.43 & ab & 1.6 & ab & 11.58 & ab & 38.4 & cd \\
II & 4.13 & gef & 3.07 & efg & 1.35 & cd & 7.2 & de & 42.54 & ab \\
JJ & 3.8 & fgh & 2.45 & gh & 1.54 & abc & 6.25 & fe & 39.41 & bcd \\
KK & 3.3 & gh & 2.08 & h & 1.57 & abc & 5.38 & $\mathrm{f}$ & 38.97 & bcd \\
LL & 3.38 & gh & 2.32 & gh & 1.48 & abcd & 5.71 & fe & 40.39 & abcd \\
MM & 2.81 & h & 2.22 & h & 1.26 & d & 5.04 & f & 44.13 & a \\
\hline
\end{tabular}

Table 4. Eigenvalues, cumulative variance and variance of 2 PCA

\begin{tabular}{lcc}
\hline \multicolumn{1}{c}{ Karyotype traits } & PCA1 & PCA2 \\
\hline TL & 0.30 & 0.94 \\
arm ratio & 0.99 & -0.09 \\
SA & 0.12 & 0.98 \\
LA & 0.40 & 0.90 \\
CI & -0.99 & 0.07 \\
$A_{1}$ & 0.99 & -0.05 \\
$A_{2}$ & 0.56 & -0.64 \\
TF & -0.99 & 0.07 \\
Syi & -0.99 & 0.06 \\
A & 0.99 & -0.07 \\
\hline Eigenvalues & 6.534 & 3.129 \\
Variance & 65.34 & 31.28 \\
Cumulative variance & 65.34 & 96.63 \\
\hline
\end{tabular}

these genotypes.

Mean comparison by Duncan's method in Table 3 shows there is at least some overlap between genotypes for the whole length of the chromosome. For TL, the lowest and highest amounts related to genotypes were 13 and 6 respectively.

In order to determine the role of each trait in genotype variation, PCA was performed (Table 4). Two primary components represented $96.41 \%$ of the total variation. The first component with $65.34 \%$ of total variation represented Arm Ratio, CI, $A_{1}$, TF, Syi and A. The second component with $31.28 \%$ of total variation represented TL, S, L and $A_{2}$.

Cluster analysis by paired group method was performed to cluster genotypes. With $99 \%$

similarity all genotypes divided into 4 clusters. Based on a dendogram, genotypes $(8,10)$ which located in the farthest group had the most asymmetric chromosome structure and the most genetic distance. This non-coordination leads to genomic incompatibility such as weakness in the fertility of offspring. Genotypes 10 and $11(2 n=20)$ and $12(2 n=18)$ are grouped in 1 cluster. Also, genotype $13(2 n=18)$ is located in a separated cluster near to genotypes 8,12 and 10 .

\section{References}

Arumuganathan, K. and Earle E. D. 1991. Nuclear DNA content of some important plant species. Plant. Mol. Biol. Rep. 9: 208-218

Broughton W.J., Hernández G., Blair M., Beebe S., Gepts P., Vanderleyden J. 2003. Beans (Phaseolus spp.)—model food legumes. Plant Soil 252: 55-128

Gepts, P., Aragao, F. and Barros 2008. Genomics of Phaseolus, A Major Source of Dietary Protein and Micronutrient. In: Moor, P. H., Ming, R. (eds.). Genomics of Tropical Crop Plants. Springer, Berlin. pp. 113-143.

Kami, J., Poncet, V., Geffroy, V. and Gepts, P. 2006. Development of four phylogenetically-arrayed BAC libraries and sequence of the APA locus in Phaseolus vulgaris. Theor. Appl. Genet. 112: 987-998

Mercado-Ruaro, P. and Delgado-Salinas, A. 1998. Karyotypic studies on species of Phaseolus (Fabaceae: Phaseolinae). Amer. J. Bot. 85: 1-9.

Paszko, B. 2006. A critical review and a new proposal of karyotype asymmetry indices Plant Syst. Evol. 258: 39-48. 
Pedrosa-Harand, A., Kami, J, Gepts, P., Geffroy, V and Schweizer, D. 2009. Cytogenetic mapping of common bean chromosomes reveals a less compartmentalized small-genome plant species. Chromosome Res. 17: 405-417.

Seijo, J. G. and Fernandez, A. 2003. Karyotype analysis and chromosome evolution in South American species of Lathyrus (Leguminosae). Am. J. Bot. 90: 980-987.

Vanhouten, W. and MacKenzie, S. 1999. Construction and characterization of a common bean bacterial artificial chromosome library. Plant Mol. Biol. 40: 977-983. 